Revista de Estudios Histórico-Jurídicos

[Sección historia del derecho europeo]

XLIII (Valparaíso, Chile, 2021)

[pp. 287-314]

\title{
INTENDENTES VERSUS ALCALDES MAYORES. LOS CONFLICTOS DE COMPETENCIAS EN LAS NuEVAS Poblaciones de Sierra Morena y Andalucía
}

[Intendants versus Mayors. The conflicts of jurisdiction in the New Settlements of Sierra Morena and Andalusia]

\author{
Adolfo Hamer Flores* \\ Universidad Loyola Andalucía, España
}

\begin{abstract}
RESUMEN
La introducción de los intendentes en la España del siglo XVIII por parte de la nueva dinastía de los Borbones, aunque fue elemento importante en su avance centralizador también implicó numerosos conflictos de competencias con las viejas autoridades territoriales. Una realidad que también estuvo presente en la Intendencia de las Nuevas Poblaciones de Sierra Morena y Andalucía a finales de ese siglo y comienzos del siguiente a través de los problemas suscitados entre el intendente, y su subdelegado en La Carlota, y los alcaldes mayores existentes en esta jurisdicción. En este trabajo analizaremos, por tanto, el origen de estas disputas, cómo se plasmaron en el día a día de esa jurisdicción y cuál fue la intervención del gobierno para remediarlas; con ello contribuiremos a un mejor conocimiento de la problemática que conllevó la implantación de este nuevo cargo.
\end{abstract}

\begin{abstract}
The introduction of intendants into 18th-century Spain by the new Bourbon dynasty, although it was an important element in its centralizing advance, it also involved numerous conflicts of powers with the old territorial authorities. A reality that was also present in the Intendancy of the New Settlements of Sierra Morena and Andalusia at the end of that century and the beginning of the next through the problems raised between the intendant, and his subdelegate in La Carlota, and the existing mayors in this jurisdiction. In this paper, therefore, we will analyze the origin of these disputes, how they took shape in the day-to-day life of that jurisdiction and what was the government intervention to remedy them; with this we will contribute to a better understanding of the problems caused by the implementation of this new emploiment.
\end{abstract}

* Doctor en Patrimonio por la Universidad de Córdoba (España). Universidad Loyola Andalucía. Departamento de Humanidades y Filosofía. ahamer@uloyola.es. ORCID 00000001-5216-5470 
Palabras Clave

Intendencia - alcalde mayor - conflicto de competencias - España - Edad Moderna.
KEY WORDS

Intendancy - Mayor - conflict of jurisdiction - Spain - Modern age.

RECIBIDO el 13 de septiembre de 2020 y ACEPTADO el 5 de octubre de 2020

\section{INTRODUCCIÓN}

La puesta en marcha, a partir de 1767, de la colonización de las Nuevas Poblaciones de Sierra Morena y Andalucía constituye uno de los hitos principales, en materia de reforma agraria, del reinado del monarca Carlos III y, por extensión, de todo el siglo XVIII español ${ }^{1}$. No solo logró pasar del planteamiento teórico al práctico, sino que, además, se concibió por sus principales impulsores (Campomanes, Aranda y Olavide) como una plasmación de la voluntad por recuperar las regalías del rey frente a los poderes tradicionales: la nobleza y el clero. Estos sectores privilegiados se habían convertido en grandes propietarios agrícolas, explotando de manera poco eficiente sus tierras y siendo los responsables de que hubiera enormes extensiones desiertas dentro de los territorios de la Corona. Frente a ello, se aspiraba a incrementar el número de pequeños propietarios satisfechos y felices con lo que poseían, con lo que se reduciría la emigración de los campesinos a los núcleos urbanos en épocas de carestía, evitando las consiguientes tensiones sociales. No puede sorprender, por tanto, que la norma suprema que se dictó para esta nueva jurisdicción, conocida como Fuero de Población de 1767, contuviera bastantes medidas reformistas como, por ejemplo, la prohibición de dividir o acumular los lotes de tierra, la de amortizar bienes rústicos o urbanos, la de establecer conventos o monasterios y la de enajenar o heredar cualquier cargo o empleo público.

En esta misma línea, la estructura de gobierno con la que nacieron fue la de una superintendencia (transformada en 1784 en intendencia), toda una declaración de intenciones en lo que respecta al deseo de centralizar y supervisar directamente el proyecto por parte de la Corona. Todavía más, al no existir la figura del corregidor en esta nueva jurisdicción, la delimitación de funciones realizada en noviembre de 1766, en teoría, no le afectaba. El superintendente de las Nuevas Poblaciones reuniría en su persona unas atribuciones que en las res-

\footnotetext{
${ }^{1}$ Para una primera aproximación al origen y devenir de estas colonias es imprescindible la consulta de: AlCÁzar Molina, Cayetano, Las colonias alemanas de Sierra Morena Notas y documentos para su historia) (Madrid, Universidad de Murcia, 1930); SÁnchez-Batalla Martínez, Carlos, La Carolina en el entorno de sus colonias gemelas y antiguas poblaciones de Sierra Morena. Prehistoria a 1835 (Jaén, Caja Rural de Jaén, 1998-2003); Hamer Flores, Adolfo, La Intendencia de las Nuevas Poblaciones de Sierra Morena y Andalucia, 1784-1835. Gobierno y administración de un territorio foral a fines de la Edad Moderna (Córdoba, Universidad de Córdoba, 2009); y PÉrez-Schmid FernÁndez, Francisco José, Colonos y propietarios de las Nuevas Poblaciones de Sierra Morena (Sevilla, Fundación de Municipios Pablo de Olavide, 2020).
} 
tantes Intendencias estaban distribuidas entre los intendentes y los corregidores. Precisamente esta circunstancia fue la que motivó los conflictos de competencias que analizaremos en el presente trabajo, ya que la introducción, a partir de 1770, de los alcaldes mayores ${ }^{2}$ sin adaptar sus competencias a las singularidades de esta superintendencia desencadenó graves y dilatados enfrentamientos entre estos y los intendentes hasta muy avanzado el siglo XIX.

Nuestro objetivo principal aquí, por tanto, consistirá en conocer el contexto en el que se implantó el cargo de alcalde mayor en la super (intendencia) de las Nuevas Poblaciones de Sierra Morena y Andalucía, analizando la naturaleza y tipología de los conflictos competenciales que estos mantuvieron con los intendentes y sus subdelegados; del mismo modo, nos adentraremos en el rol que adoptó el gobierno central en estas disputas. Haremos uso, para ello, tanto de la escasa bibliografía existente ${ }^{3}$ como, sobre todo, de una abundante documentación inédita, recopilada durante años por el que suscribe de los legajos y libros de varios archivos estatales y territoriales españoles como, por ejemplo, el Archivo Histórico Nacional (Madrid), el Archivo General de Simancas (Valladolid) o el Archivo de la Real Chancillería de Granada.

De este modo, estaremos en disposición de dar respuesta a uno de los aspectos peor conocidos de la historia neopoblacional y cuya relevancia está fuera de toda duda, como lo prueba el hecho de que ya en la propia época que analizamos se mencionara este asunto como uno de los problemas de mayor gravedad. Circunstancia, esta última, señalada recurrentemente por los investigadores, aunque siempre de manera escueta y puntual, limitándose solo a dejar constancia de lo que el intendente Pedro Polo de Alcocer narró en un informe fechado en 1833 y dirigido al ministerio de Fomento ${ }^{4}$; algo especialmente llamativo para el caso de las Nuevas Poblaciones de Andalucía, por ser donde los conflictos fueron más intensos y prolongados. Los principales trabajos dedicados a la historia colonial de tres de las cuatro feligresías de este partido territorial o no mencionan su exis-

\footnotetext{
${ }^{2}$ Este empleo no se incluyó entre los detallados en su carta puebla: Real Cédula de Su Magestad y señores de su Consejo que contiene la Instrucción, y fuero de población, que se debe observar en las que se formen de nuevo en la Sierramorena con naturales, y estrangeros Católicos. Año 1767 (Madrid, Oficina de Antonio Sanz, 1767). Se incorporó de manera incompleta, al eliminarse 20 de sus 79 artículos, en la Novísima Recopilación (libro VII, título XXII, ley 3). Una transcripción íntegra en: Hamer Flores, Adolfo (ed.), Legislación Histórica Neopoblacional. Disposiciones normativas emanadas del poder central en las Nuevas Poblaciones de Sierra Morena y Andalucía (1767-1835) (Madrid, Bubok Publishing, 2018), pp. 55-77.

${ }^{3}$ Esta circunstancia afecta no solo al caso concreto que aquí estudiamos, pues aunque abundan los estudios centrados en intendencias y alcaldías mayores concretas, los análisis globales son significativamente más escasos: ABBAD, Fabrice et OzAnAm, Didier, Les intendants espagnols du XVIIIe siècle (Madrid, Casa de Velázquez, 1992); Álvarez y Cañas, María Luisa, Los corregidores de letras en la administración territorial andaluza del siglo XVIII, en Revista de Historia Moderna, 13-14 (1995), pp. 123-149.; ÁlvareZ y CAÑAS, María Luisa, Corregidores y alcaldes mayores: La administración territorial andaluza en el siglo XV III (Alicante, Publicaciones de la Universidad de Alicante, 2012).

${ }^{4} \mathrm{La}$ mayor parte de los investigadores han citado este informe a partir de la transcripción incluida en una obra editada a finales de los años veinte del pasado siglo XX: BERNALDO DE Quirós, Constancio, Los reyes y la colonización interior de España desde el siglo XVI al XIX (Madrid, Imprenta Helénica, 1929), pp. 56-90.
} 
tencia ${ }^{5}$ o se limitan a consignar la creación de los alcaldes mayores en $1770^{6}$ y que mantuvieron conflictos con la intendencia ${ }^{7}$. En lo que concierne a las colonias de Sierra Morena, lo habitual es que no se mencione la creación de estos empleos ${ }^{8}$ o solo se incluya una referencia sucinta a su creación y problemas siguiendo al ya mencionado Polo de Alcocer ${ }^{9}$, con la única excepción de las investigaciones de Cayetano Alcázar Molina ${ }^{10}$ y Carlos Sánchez-Batalla ${ }^{11}$ que, aunque siguen la misma tendencia de apoyarse en la referida memoria, mencionan alguna otra información puntual de archivo como, por ejemplo, la concordia de mayo de 1804. Por último, no podemos dejar de señalar el hecho, bastante sorprendente pero muy sintomático del escaso interés por esta cuestión, de que solo se mencione de pasada el asunto que aquí nos ocupa en un estudio biográfico dedicado precisamente al alcalde mayor que firmó la referida concordia ${ }^{12}$.

$\mathrm{Al}$ dejar constancia estas investigaciones tan solo de que Pablo de Olavide habría cometido un error al fomentar, en teoría, la creación de unas varas que después levantaron "polvareda de guerras y disgustos contra las autoridades directivas de la empresa, duraderas hasta ahora" y de la gravedad de estas disputas durante la intendencia de Tomás José González Carvajal ${ }^{13}$, se ha dejado de lado el abordar cuestiones de tanto interés como explicar el origen de ese enfrentamiento y cómo se manifestó, elementos ambos necesarios para poder evaluar su importancia. Hace algunos años, ciertamente, procedimos a realizar la primera, y única hasta la fecha, aproximación a los conflictos competenciales dentro de la intendencia de Nuevas Poblaciones, analizando también el conflicto con los alcaldes mayores ${ }^{14}$; pero en esta ocasión, sobre todo gracias a la referida localización y análisis de una abundante y pertinente documentación de archivo sobre el tema, podremos

${ }^{5}$ FILter Rodríguez, José Antonio, Inmigrantes centroeuropeos en la Andalucía del siglo XVIII. Colonos, familia, sociedad y vida cotidiana en las nuevas poblaciones de Cañada Rosal, El Campillo y La Luisiana (Sevilla, Ayuntamientos de Cañada Rosal y La Luisiana, 2018), p. 377.

${ }^{6}$ Vázquez Lesmes, Rafael, Un pueblo de alemanes en la campiña cordobesa. San Sebastián de los Ballesteros (Córdoba, Diputación de Córdoba, 2015), p. 164.

${ }^{7}$ García Cano, María Isabel, El gran proyecto ilustrado de Carlos III y Olavide. Las Nuevas Poblaciones de Andalucia (Fuente Palmera, 1768-1835) (Córdoba, Diputación de Córdoba, 2013), pp. 83 y 195-196.

${ }^{8}$ Capel Margarito, Manuel, La Carolina, capital de las Nuevas Poblaciones (Un ensayo de reforma socio-económica de España en el siglo XVIII) (Jaén, Instituto de Estudios Giennenses, 1970).

${ }^{9}$ López de Sebastíán, José, Reforma agraria en España. Sierra Morena en el siglo XVIII (Madrid, Editorial ZYX, 1968), pp. 101 y 120; PéreZ-SAuquillo y CÁdIZ, Carlos, Historia de La Carolina, antigua capital de las Nuevas y Reales Poblaciones de Sierra Morena, en ÉL Mismo, Antología breve (Trabajos inéditos) (Sevilla, Librería San José, 1970), pp. 84-85.

${ }^{10}$ Alcázar Molina, Cayetano, cit. (n. 1), pp. 30-31, 48 y 75.

${ }^{11}$ Sánchez-Batalla Martínez, Carlos, cit. (n. 1), IV, pp. 113-118 y 480-483.

${ }^{12}$ Martínez Aguilar, Joaquín, Ignacio Pablo Sandino de Castro (1766-1833). Abogado, alcalde mayor de La Carlota, diputado en Cortes. Ampliaciones a su bibliografía, en VÁzQuez Lesmes, Rafael y Villas Tinoco, Siro (coords.), Actas del VI Congreso Histórico sobre Nuevas Poblaciones (Córdoba, Junta de Andalucía, 1994), pp. 330-331.

${ }^{13}$ Bernaldo de Quirós, Constancio, cit. (n. 4), pp. 64 y 72-73.

${ }^{14}$ Hamer Flores, Adolfo, cit. (n. 1), pp. 31-42. 
profundizar hasta ofrecer respuestas que consideramos prácticamente definitivas a no pocos interrogantes.

\section{Alcaldes mayores para las Nuevas Poblaciones de Sierra Morena y ANDALUCÍA: ESTABLECIMIENTO Y ATRIBUCIONES}

Concebida como una comisión temporal, aunque acabó asentándose y su vigencia se extendió hasta 1835, la superintendencia de las Nuevas Poblaciones nació en julio de 1767 siguiendo el espíritu del sistema de intendencias impulsado en 1749 y que había sido modificado pocos meses antes. A pesar de la eficacia de estos nuevos funcionarios, que empezaron a nombrarse en 1711, la antigua burocracia les mostró su oposición, especialmente en el caso de los jueces y personal jurídico al sentir usurpadas sus funciones; de ahí la retirada de esas competencias judiciales en 1720. Pero las nuevas ordenanzas de octubre de $1749^{15}$, además de vincularlos a las secretarías de Guerra y de Hacienda, restablecieron plenamente el sistema de intendentes en la Península, de resultas de lo cual sus funciones de hacienda, policía y guerra se reforzaban con las de justicia. En Castilla el choque con los corregidores sería nuevamente inevitable, de ahí la decisión de que los intendentes asumieran los corregimientos de las capitales y absorbieran sus funciones ${ }^{16}$.

No obstante, estos enfrentamientos, sumados a las dificultades para que un único individuo atendiese tantas ocupaciones, facilitaron la promulgación de la real cédula de 13 de noviembre de 1766, que introdujo una importante modificación al separar los corregimientos de las intendencias; reservándose para estos últimos solo Hacienda y Guerra, y señalándose a aquellos lo concerniente a Justicia y Policía ${ }^{17}$. En las Nuevas Poblaciones, como ya indicamos, el Fuero de 1767 no establecía la creación inmediata de corregidores ni de alcaldes mayores, por lo que hacía recaer en la superintendencia unas amplísimas facultades ${ }^{18}$ que, de este modo, se ocupaba también de las funciones de justicia y policía. Tanto es así que hasta finales de 1770 el superintendente Pablo de Olavide despachaba él mismo todos esos asuntos pues su formación universitaria ni siquiera hacía necesario que debiera actuar asesorado por letrados, y así podría haber continuado como ocurrió durante toda su existencia con la superintendencia de la Concepción de Almuradiel ${ }^{19}$, donde nunca hubo alcalde mayor y su superintendente asumía

${ }^{15}$ Novísima Recopilación, libro VII, título XI, ley 24.

${ }^{16}$ Juan Vidal, Josep y Martínez Ruiz, Enrique, Política interiory exterior de los Borbones (Madrid, Istmo, 2001), pp. 145-149; Pérez Estévez, Rosa María, La España de la Ilustración (Madrid, Actas Editorial, 2002), pp. 64-66.

${ }^{17}$ Novísima Recopilación, libro VII, título XI, ley 26.

${ }^{18} \mathrm{El}$ artículo 52 del Fuero de Población indicaba que "para todo lo referido, y lo demás anejo y dependiente, se le confiere plena autoridad al dicho superintendente con la facultad de subdelegar en una o más personas, con absoluta inhibición de todos los intendentes, corregidores, jueces y justicias, y con sujeción únicamente al Consejo en sala primera de gobierno, y en lo económico a la Superintendencia General de la Real Hacienda”.

${ }^{19}$ Sobre el origen y evolución posterior de esta Superintendencia, que para economizar gastos se confirió, a partir de 1793, a los que desempeñaban el cargo de intendente de las 
también la jurisdicción ordinaria ${ }^{20}$; pero el limeño, consciente, al parecer, de que el volumen de asuntos y pleitos le hacía muy difícil el disponer de un tiempo muy necesario para las labores de puesta en marcha y gobierno de las nuevas colonias, sumado al hecho de que no todos sus subalternos disponían de formación en derecho, decidió nombrar dos asesores para que prestaran sus servicios en los juzgados de las dos capitales de esta jurisdicción. Unos nombramientos realizados en virtud de las competencias que le confería el Fuero, entendiendo el propio Olavide que a todos los efectos eran alcaldes mayores, aunque bajo sus órdenes ${ }^{21}$. Es muy probable que el superintendente no tuviera margen suficiente para gestionar su nombramiento como alcaldes mayores mediante real orden por la vía del ministerio de Hacienda; es decir, unas designaciones realizadas por vía diferente a las del resto de alcaldías mayores de Castilla. Fórmula nada extraña en las colonias por su peculiar sistema de gobierno. Gran parte de sus empleados, sobre todo los que ejercían labores de gobierno o manejaban grandes sumas de dinero, veían confirmado su nombramiento por real orden a propuesta de la intendencia, realizada por vía del ministerio de Hacienda; incluso los eclesiásticos cuando a comienzos del siglo XIX pasaron a elegirse por el mismo sistema que en el resto del país, nunca recibieron su nombramiento por la secretaría de Gracia y Justicia sino por la de Hacienda ${ }^{22}$.

Pero la visita de inspección de Pedro José Pérez Valiente, con el consiguiente cese temporal de Olavide desde abril hasta agosto de 1769, trastocó completamente esta y otras muchas decisiones y proyectos del superintendente. El Consejo de Castilla sugirió la creación de alcaldes mayores en la instrucción de 6 de julio de 1770, la cual se hizo efectiva en octubre de ese mismo año ${ }^{23}$; aunque con la particularidad de que sus nombramientos se alejarían de lo dispuesto en el artículo 51 del Fuero ${ }^{24}$. De este modo, será el Consejo de Castilla, a través de la secretaría de Gracia y Justicia, el que proveerá las dos varas de estas nuevas

Nuevas Poblaciones de Sierra Morena y Andalucía véase SÁnchez-Batalla Martínez, Carlos, Almuradiel y Venta de Cárdenas. Apuntes históricos (Ciudad Real, Ayuntamiento de Almuradiel y Asociación de Venta de Cárdenas, 2005).

${ }^{20}$ Archivo Histórico Nacional, Madrid (en adelante AHN), Fondos Contemporáneos, Gobernación, leg. 295, exp. 12. Nos informa de ello el intendente Pedro Polo de Alcocer en carta sin fecha, pero, a tenor de su contenido, de en torno a 1816 y dirigida al secretario de Estado y del Despacho de Hacienda.

${ }^{21}$ Olavide manifestaba en septiembre de 1770 que "uno y otro no solo son asesores sino también alcaldes mayores por nombramiento que yo les conferí, y que refrendó el visitador [Pérez Valiente] cuando fue dueño de su jurisdicción" (AHN, Inquisición, leg. 3605, s.f.).

${ }^{22}$ AHN, Fondos Contemporáneos, Gobernación, leg. 295, exp. 12.

${ }^{23}$ Las advertencias que Pablo de Olavide realizó en septiembre de ese mismo año al presidente del Consejo de Castilla sobre los problemas que desencadenarían estos nombramientos no surtieron ningún efecto (AHN, Inquisición, leg. 3605, s.f. Carta de Pablo de Olavide al conde de Aranda, 26 de septiembre de 1770).

24 “Siendo preciso que tenga bajo de su mano el superintendente personas respetables y de talento que le ayuden en los diferentes puntos y parajes en que a un tiempo se estarán demarcando y levantando las Nuevas Poblaciones, quedará en su libertad elegirlas y subdelegarles aquella autoridad y facultades que tenga por conveniente; y asimismo podrá nombrar [...] cualesquiera empleos necesarios al todo de la empresa, asignándoles los salarios o ayudas de 
colonias y expedirá los nombramientos en los mismos términos que el resto de estos magistrados, con lo que no se tenían en cuenta las particularidades de esta Intendencia y se sentaban las bases para todas las disputas y conflictos posteriores.

En los primeros años esas disputas fueron escasas, seguramente tanto por el carácter prudente de los magistrados como por la circunstancia de ejercer el de Sierra Morena en un ámbito donde había un superintendente y, a partir de 1778, un subdelegado que interinamente ejercía estas funciones; y en las de Andalucía, un subdelegado con graduación de intendente de provincia. No obstante, el interés que el subdelegado Ondeano mostró en 1782 por sugerir un candidato para la vara de La Carolina y la mala opinión que mostró del que finalizaba su trienio nos muestran que incluso en este contexto las relaciones entre ambas autoridades podían llegar a ser difíciles ${ }^{25}$, como de nuevo sucedería a comienzos del siglo XIX. No obstante, fue la transformación de la superintendencia en intendencia en septiembre de 1784 la que prendió la mecha de los conflictos más graves y duraderos, pues los sucesivos intendentes residieron la mayor parte del tiempo en las colonias de Sierra Morena, con lo que al frente de las Nuevas Poblaciones de Andalucía quedó solo un subdelegado que gobernaba en su nombre. Algunos alcaldes mayores de La Carlota consideraron que, en ausencia de aquel, en dichos subdelegados solo podían recaer los asuntos de Hacienda, debiendo ejercer ellos el resto de las funciones de gobierno y justicia. No en vano estos entendían, desde 1766, en el resto de la Corona en esos ámbitos, ya que como letrados intervenían cualificadamente en todos los asuntos concernientes al gobierno del pueblo; por lo que no estuvieron dispuestos a aceptar fácilmente que el intendente de las Nuevas Poblaciones, y sobre todo su subdelegado en su ausencia, pudiera asumir por completo las funciones de los corregidores ${ }^{26}$, incluidas las labores de justicia civil y criminal, desde el momento en que se implantaron las varas de alcaldes mayores en las nuevas colonias. Por su parte, la intendencia, amparándose en el Fuero, ya que nunca se suprimieron o limitaron sus atribuciones, siempre defendió que las competencias de los alcaldes mayores se circunscribían solo a lo criminal, pudiendo ejercer en lo civil no como jueces sino únicamente como asesores del juzgado de la intendencia.

\section{Creación y atribuciones de los alcaldes mayores (1770)}

La creación de alcaldes mayores, como ya expusimos, se recogió en la instrucción de 6 de julio de 1770, emitida por el Consejo de Castilla como conclusión a la visita realizada el año anterior, en concreto desde el artículo 37 hasta el 42. En ellos se hacía referencia a la posibilidad de crear estas varas, que asumirían

costa oportunas; de lo cual formará un rol o matrícula firmada para que se les libren conforme a ella, dando noticia a la vía reservada de Hacienda".

${ }^{25}$ Archivo General de Simancas (en adelante AGS), Secretaria y Superintendencia de Hacienda, leg. 502 , docs. 30 y 34 .

${ }^{26}$ Los alcaldes mayores, como tenientes de corregidores que eran, asumían habitualmente las funciones del corregidor durante sus vacantes, enfermedades o ausencias; tal y como nos informa Bernardo Ares, José Manuel, Los alcaldes mayores de Córdoba (1750-1833) (Córdoba, Publicaciones del Monte de Piedad y Caja de Ahorros de Córdoba, 1978), p. 40. 
las funciones que hasta entonces habían tenido los dos asesores nombrados por Olavide, señalando la conveniencia de que hubiera una para Sierra Morena y otra para Andalucía (art. 37). Se especificaba que "será propia y privativa de los alcaldes mayores la administración de justicia en lo contencioso, civil y criminal, quedando a cargo del superintendente y sus subdelegados lo tocante a Hacienda, Policia y Economía; bien que, si en estos puntos ocurrieren algunos procedimientos judiciales, serán dichos alcaldes mayores sus asesores ordinarios" (art. 38). Una propuesta de delimitación de competencias que sus redactores sabían que generaría conflictos por lo que además se dispuso que observarían "reciprocamente la mejor correspondencia y armonía estos alcaldes mayores con el superintendente y sus subdelegados, considerando los mutuos auxilios que podrán y deberán darse en los negocios que ocurran" (art. 39) ${ }^{27}$.

No transcurrió mucho tiempo entre la comunicación oficial de esta instrucción, que tuvo lugar a comienzos del mes de septiembre, y la puesta en marcha de lo que disponía sobre los alcaldes mayores. Se procuró, eso sí, que esta innovación no alterase excesivamente el funcionamiento de las colonias. De ahí que el secretario de la Cámara de Castilla solicite el día 7 de ese mes a Olavide los nombres y méritos de los que entonces eran asesores, informando el superintendente el día 26 de que esos empleos los desempeñaban Pablo Antonio Collado en las colonias de Sierra Morena, nombrado el 31 de mayo de 1768, y Luis de Herrera en las Andalucía, con nombramiento fechado el 16 de marzo de $1769^{28}$; asimismo, propuso que recayera en estos ese nombramiento ${ }^{29}$. Unos días más tarde, tras la pertinente consulta del Consejo de Castilla, el rey decidió crear dos alcaldes mayores, dando orden el 13 de octubre de 1770 para que se estableciese uno en las Nuevas Poblaciones de Sierra Morena y otro en las Nuevas Poblaciones de Andalucía; siendo designados como tales los asesores existentes y asignándoles los mismos salarios de 600 y 500 ducados anuales, respectivamente, que ya cobraban por su anterior ocupación. En lo que concierne a sus atribuciones, como lo demuestra el contenido de uno de esos títulos de alcalde mayor, dispuso que podían "usar libremente este oficio y ejecutar mi justicia por sí y sus oficiales, y oir, librar y determinar los pleitos, negocios causas civiles y criminales que en esas Nuevas Poblaciones estén pendientes y ocurrieren" 30 .

Así pues, las competencias de los intendentes (y sus subdelegados) y las que tenían en teoría los dos alcaldes mayores de esta jurisdicción no solo quedaron sin definir adecuadamente a partir de entonces, sino que incluso se superponían. De ahí que no faltaran peticiones como la realizada por el intendente Hermenegildo Llanderal en 1809 para que "en los titulos de dichos alcaldes mayores [de Sierra Morena] $y$ de las Poblaciones de Andalucia se prevenga que hayan de entender únicamente en los asuntos

${ }^{27}$ AHN, Fondos Contemporáneos, Gobernación, leg. 328, exp. 23. Se incluye transcripción de este documento en: Alcázar Molina, Cayetano, cit. (n. 1), pp. 147-159; López de Sebastián, José, cit. (n. 9), pp. 209-224; y Hamer Flores, Adolfo (ed.), Legislación, cit. (n. 2), pp. 123-138.

${ }^{28}$ AHN, Inquisición, leg. 3608, s.f.

${ }^{29}$ AHN, Inquisición, leg. 3605, s.f.

${ }^{30}$ Archivo de la Real Chancillería de Granada (en adelante ARChG), cabina 321, leg. 7308, pieza 1. Nombramiento de Juan Fernández de Mesa, en lugar de Juan Meléndez Valdés, fechado en 18 de septiembre de 1777. 
criminales y los civiles convencionales que no toquen de manera alguna en lo directivo, económico, politico y discernimiento de los derechos de sucesión de los colonos en las suertes o terrenos que se les han repartido, por ser todo esto privativo del superintendente de las citadas Poblaciones en virtud del real Fuero, para cortar las frecuentes y ruidosas desavenencias que ha babido entre aquellos y el subdelegado con grave perjuicio del real servicio y felicidad de los mismos colonos" 31 ; no obstante, estos intentos de eliminar el problema a partir de un cambio en la redacción de los títulos nunca lograron alcanzar su objetivo.

\section{La transformación de la superintendencia en intendencia: el inicio de la etapa dorada} de conflictos

Sin ningún atisbo de duda, los problemas de definición de competencias entre la intendencia y los alcaldes mayores de La Carolina y La Carlota dieron lugar al conflicto de este tipo más importante de cuantos hubo en el seno de las Nuevas Poblaciones, llevándose la peor parte las situadas en Andalucía. Todo parece indicar, incluso el último intendente de las colonias, Pedro Polo de Alcocer, así lo pensaba ${ }^{32}$, que el origen de esas desavenencias de la intendencia y, sobre todo, su subdelegación de La Carlota con los alcaldes mayores arrancó de la transformación de la superintendencia en intendencia en septiembre de $1784^{33}$. Pensamiento que parece verse corroborado por la no constatación de pleitos de este tipo con anterioridad a dicha fecha. Al contrario, hasta entonces la relación entre ellos se podría definir como buena.

Un primer aviso de lo que se avecinaba lo encontramos en un testimonio de Pedro Tomás Álvarez, alcalde mayor de La Carlota, que en 1787 afirmaría que "las facultades de esta alcaldía mayor, vivo convencido, son las mismas que señala la real orden de 1766, en que se separaron los corregimientos de las intendencias (y esto entendiendo sus facultades hasta donde llegan las de los intendentes de provincia, no siéndolo esta Intendencia como no lo es y sí solo una comisión particular con este título, motivo por [el] que no se pone en la Guia); la cual deja solamente a estas lo perteneciente a la dirección de los colonos en punto a la conservación de sus yuntas, repartimiento de suertes y edificación y reedificación de sus casas. Tiene también el intendente aqui las comisiones de caminos y pósito" ${ }^{34}$. En consecuencia, los problemas no se dejarían esperar mucho; concentrándose especialmente en esa colonia, ya que allí los alcaldes mayores no se mostraron dispuestos a estar bajo la autoridad de quien ellos consideraban solo como un simple subdelegado de rentas. Tanto es así que mientras que únicamente hemos localizado algunas referencias puntuales a problemas en las colonias de Sierra Morena ${ }^{35}$, para las de Andalucía los testimonios son muy abundantes.

${ }^{31}$ AHN, Consejos, leg. 11992, exp. 2. Carta de Francisco de Saavedra al decano del Consejo Supremo de España e Indias.

${ }^{32}$ AHN, Fondos Contemporáneos, Gobernación, leg. 2738, doc. 16; y leg. 295, exp. 12.

${ }^{33}$ AHN, Fondos Contemporáneos, Gobernación, leg. 279, exp. 6.

${ }^{34}$ Biblioteca Nacional de España (en adelante BNE), ms. 7294, f. 402r. y v.

${ }^{35}$ Así sucede, por ejemplo, en enero de 1815 cuando Polo de Alcocer ordenó arrestar a Juan Lucas, alcalde pedáneo del $4^{\circ}$ departamento de La Carolina, por haberse negado a cumplir un decreto suyo. El alcalde mayor, José Flórez Villamil, intervino en el asunto no tanto, aunque también, porque considerase que los alcaldes pedáneos estaban bajo su autoridad antes que bajo la del intendente, sino porque se había cometido el atropello de encarcelarlo sin que antes 
El primer enfrentamiento que hemos podido localizar entre el subdelegado y el alcalde mayor de La Carlota, tuvo lugar en 1789. Lamentablemente, casi no tenemos datos sobre él, a excepción de que se debió a una causa formada al administrador de correos y al maestro de postas de la referida colonia ${ }^{36}$. Ondeano informó al ministro de Hacienda, Pedro de Lerena, el 15 de septiembre del procedimiento incoado por el alcalde mayor de La Carlota contra Pedro Carreras, oficial de la Contaduría y administrador de Correos, y José Guerrero, maestro de postas, por una representación sobre la conducta de los principales empleados de esa colonia que tenía empezada el primero para dirigirla a dicho ministro ${ }^{37}$. El intendente se la había pedido por carta de 14 de septiembre para que se la remitiera a fin de informar de lo que resultase al ministro, pero el alcalde mayor se negó a remitirle los autos al no considerarlo juez competente para el conocimiento del asunto, aunque también tuviera las funciones de subdelegado de Correos en las Nuevas Poblaciones. La respuesta de Ondeano no se hizo esperar, escribiendo al conde de Floridablanca a comienzos de octubre para que diese orden al alcalde mayor para que se inhibiera en esa causa como debía "por gozar los dependientes de correos y postas del fuero activo y pasivo en todas sus causas civiles y criminales, y no ser la presente de las exceptuadas"; mientras tanto, Pedro Tomás Álvarez ${ }^{38}$ se acogía a la ley $3^{\text {a }}$, título 9, partida $7^{\mathrm{a}}$ de las Partidas donde se indica que el que infamase a otro con un líbelo público o secreto debe ser castigado igual que el que lo publicase. Además, sostuvo que los detenidos habían confesado estar coaligados con los colonos de Monte Alto, uno de los diseminados de esa colonia, con lo que estarían comprendidos en lo contenido en el auto acordado del Consejo de 1 de abril de 1767 en que declara sediciosos a los que guiados de maligno espíritu esparcen cizaña, falsas voces y rumores contra los magistrados. Ahora bien, el alcalde mayor, probablemente movido por los graves errores que cometió durante la instrucción de los autos ${ }^{39}$, que fueron hábilmente identificados por el intendente

entregase la vara de su cargo; ya que con este proceder el "agraviado y ofendido" había sido el rey, "como representado en el bastón de justicia con que se le arresto". Flórez Villamil no podía, por tanto, consentir que un representante de la jurisdicción ordinaria permaneciese en prisión portando la vara en su mano, así que procedió a liberarlo. Esta iniciativa desagradó a Polo de Alcocer, que se quejó al ministerio de Hacienda, pero ambos convinieron en que una vez que el alcalde mayor le hubiese retirado la vara al alcalde pedáneo, se lo entregaría para que pudiera ser juzgado por su falta. Y así ocurrió, dictaminando finalmente el rey por real orden de 16 de mayo que se le privase durante diez años de cualquier empleo de justicia (AHN, Fondos Contemporáneos, Gobernación, leg. 332, exp. 3). Ahora bien, no parece que este fuera el único episodio protagonizado por este alcalde mayor, de quien Polo de Alcocer afirmaría en 1817 que, durante su alcaldía, se había ocupado de pequeñeces y de hacer la guerra a la Intendencia al igual que lo hacía entonces su homónimo en La Carlota (AHN, Fondos Contemporáneos, Gobernación, leg. 279, exp. 10).

${ }^{36}$ AHN, Fondos Contemporáneos, Gobernación, leg. 308.

${ }^{37}$ Una transcripción del texto de esta representación en HAMER Flores, Adolfo, cit. (n. 1), pp. 129-135.

${ }^{38}$ Alcalde mayor de La Carlota desde 1785 hasta 1792.

${ }^{39} \mathrm{El}$ alcalde mayor no pudo probar que hubiera difusión del contenido del papel, ni siquiera entre los colonos que mencionaba de Monte Alto, ya que la representación que estos dirigieron al rey recogía quejas diferentes. Del mismo modo, la declaración de Carreras se tomó en minuta sin pasarla a limpio inmediatamente para que la firmase, de ahí que después este se negara a 
y dificultaban que el proceso no se sobreseyese en instancias superiores, acabó entregándoselos el 9 de octubre, sin que tengamos noticia de cómo se acabó resolviendo esta cuestión una vez que se remitió a Madrid ${ }^{40}$.

Otro conflicto de relevancia tendría lugar en 1793, cuando el intendente acusó al alcalde mayor Francisco de Paula Padial ${ }^{41}$ de haber actuado, sin competencias para ello, contra el administrador de la estafeta de Correos de La Luisiana, usurpando la jurisdicción privativa de la intendencia. Un episodio que no suponía, ni mucho menos, el primero protagonizado por Padial pues en enero de ese mismo año el intendente Ondeano había dado cuenta al ministro de Hacienda de otros problemas previos. La tensión entre ambos era tal que el intendente no dudó en calificar, en noviembre de 1794, al alcalde mayor como "ignorante, ambicioso y arrojado juez, consentido sin duda en la impunidad de sus enormes gravísimos anteriores atentados cuya resolución está pendiente". La tardanza en dar respuesta a sus quejas lo animaban, a su juicio, en ese pulso que mantenía con la intendencia ${ }^{42}$.

Ahora bien, a estos dos ejemplos le sucederían un sinnúmero de pleitos más; y aunque a nosotros apenas nos han llegado referencias concretas sobre gran parte de ellos ${ }^{43}$, el conocido testimonio de Polo de Alcocer, datado en 1833, nos muestra bastante bien su gravedad: "Desentendiéndose estos alcaldes del sistema fundamental de Poblaciones, y viéndose sin negocios en qué ocuparse como no ocurriese algo de lo criminal, se unieron ellos y sus sucesores para hacer viva guerra al intendente. El calor llegó a tanto en La Carlota que faltó muy poco para que ocupase la cárcel el inquieto y atrevido Sandino. Paró esto al fin en acudir ambos a la superioridad, y el rey mandó al Consejo propusiese el modo de evitar tales desavenencias" ${ }^{\prime 4}$.

firmarla aduciendo no recordar lo declarado por, supuestamente, estar enfermo; un hecho que se resolvió simplemente indicando su negativa a firmar en vez de tomarle nueva declaración.

${ }^{40}$ AGS, Secretaria y Superintendencia de Hacienda, leg. 501, docs. 56, 57, 58, 59 y 60.

${ }^{41}$ Francisco de Paula Padial fue nombrado alcalde mayor de las Nuevas Poblaciones de Andalucía en 1792, ejerciendo esta vara hasta aproximadamente 1798.

${ }^{42}$ AGS, Secretaria y Superintendencia de Hacienda, leg. 503, docs. 24 y 26.

${ }^{43}$ Disponemos, como excepción, de otros dos interesantes testimonios anteriores a la firma de la concordia de 1804. El primero nos lo ofrece en 1793 Francisco de Paula Padial, alcalde mayor de La Carlota, al darnos algunos detalles de estos enfrentamientos y señalando además que no estaba de acuerdo con las facultades que el intendente se arroga para sí, ya que consideraba que eran excesivas y que solo tenían el objetivo de desautorizarle y limitar sus competencias (AHN, Consejos, leg. 4059, exp. 5). Por otro lado, el segundo nos sitúa de nuevo en esta colonia a finales de 1803, entonces el alcalde mayor Ignacio Pablo Sandino de Castro trató de encargarse de la guardia de sanidad que se había establecido en ella para evitar la introducción de la epidemia de fiebre amarilla que entonces afectaba a Málaga aún a pesar de que el presidente de la Junta de Sanidad de La Carlota era el subdelegado; pero, finalmente, todo se decantó a favor de la Subdelegación, pues una real orden de 23 de diciembre de 1803 conminó a Sandino a abstenerse de molestar a dicha junta (AHN, Fondos Contemporáneos, Gobernación, leg. 334, exp. 6).

${ }^{44} \mathrm{AHN}$, Fondos Contemporáneos, Gobernación, leg. 2738, doc. 16. 


\section{UNA SOLUCIÓN QUE AVIVA EL CONFLICTO: LA CONCORDIA PARA LAS NUEVAS Poblaciones de Andalucía de 1804}

Los conflictos se hicieron tan frecuentes que el progreso y el día a día de las nuevas colonias no tardaron en resentirse. Esto llevó al intendente Tomás José González Carvajal ${ }^{45}$ a tratar de resolver la compleja situación por cuantos procedimientos pudo; no muy afortunados según el criterio de Polo de Alcocer. De este modo, por un lado, elevó en 1804 una representación al secretario de Estado y del Despacho de Hacienda solicitando la supresión del régimen especial de gobierno de las Nuevas Poblaciones ${ }^{46}$ a través del desarrollo del artículo 14 de su Fuero, que disponía el establecimiento de ayuntamientos en las colonias y el nombramiento, por tanto, de corregidores que impedirían al alcalde mayor disfrutar de todas las competencias que pretendían arrogarse. Es decir, para él era el momento de crear esos concejos integrados solo por colonos elegidos por sus vecinos, tanto porque las colonias ya estaban en estado de mantenerse como porque el sistema de gobierno foral era muy $\operatorname{costoso}^{47}$. La propuesta se tomó en consideración y, para resolver sobre ella, se encomendó al Consejo de Castilla, mediante real orden, que emitiese un dictamen. Para este fin, dicho tribunal dio comisión a José Enrique Luna, fiscal de la Real Chancillería de Granada, al objeto de que visitase las nuevas colonias y examinase su estado. Luna se trasladó a La Carolina, donde con bastante celeridad concluyó su comisión, informando al Consejo que las colonias estaban en tal mal estado, y sus colonos tan miserables y desnudos, que su ruina parecía inminente y recomendando la necesidad de que se tomase conocimiento exacto de la causa de dicha decadencia para poder cesar su gobierno provisional, excesivamente costoso, y proveerlas de todo lo necesario para su prosperidad en el régimen ordinario del resto de la Corona. Recibido este informe, el Consejo de Castilla trató de que se hiciese una visita general en esta intendencia; encargándosela al propio Luna por real orden de 16 de diciembre de 1804. Sin embargo, por razones que desconocemos, no la admitió; nombrándose en su lugar al abogado madrileño Andrés Crespo Cantilla, que también se excusó. De resultas de todo ello, el rey ordenó al Consejo suspender dicha visita ${ }^{48}$.

Por otro lado, González Carvajal también trató de poner punto final a las tensiones competenciales que mantenía con el alcalde mayor de La Carlota a través de la firma, el 4 de mayo de 1804, en esta colonia de una concordia entre $\operatorname{ambos}^{49}$. Un documento que constituía el resultado de un largo proceso iniciado a finales de agosto de 1801, y que se había dilatado durante varios meses hasta

\footnotetext{
${ }^{45}$ Desempeñó el cargo de intendente de las Nuevas Poblaciones de Sierra Morena y Andalucía desde 1795 hasta 1807.

${ }^{46}$ Nos informa de ello el intendente Pedro Polo de Alcocer (AHN, Fondos Contemporáneos, Gobernación, leg. 2738, doc. 16).

${ }^{47}$ VÁzquez Lesmes, Rafael, Las Nuevas Poblaciones en las Cortes de Cádiz, en Avilés Fernández, Miguel y Sena Medina, Guillermo (eds.), Carlos III y las Nuevas Poblaciones (Córdoba, Universidad de Córdoba, 1988), II, pp. 110-111.

${ }^{48} \mathrm{AHN}$, Fondos Contemporáneos, Gobernación, leg. 2738, doc. 16.

${ }^{49}$ AHN, Fondos Contemporáneos, Gobernación, leg. 334, exp. 6.
} 
que el intendente aceptó en el otoño de 1803 la propuesta de concordia que Sandino le había remitido un año antes. Un acuerdo negociado en un contexto muy complicado, en el que incluso la Intendencia había decretado el cese del salario del alcalde mayor de La Carlota por interpretar que la real orden, fechada el 14 de agosto de $1802^{50}$, de reposición en sus empleos de aquellos que huyeron de la misma durante la epidemia de fiebre amarilla de 1800 implicaba la vuelta del alcalde mayor Pedro Boada de las $\operatorname{Costas}^{51}$; y en el que se había procedido a extraer de su casa, con hombres armados y sin su aprobación, a un individuo que se había refugiado en ella para impedir su detención, precisamente un domingo a unas horas en las que la población estaba muy concurrida. Todavía más, Sandino recordaría al subdelegado Joaquín Cadiou en 11 de septiembre de 1805, al recriminarle que solo fuera un instrumento del intendente y no ejerciera por sí mismo las facultades que le cedió, el habérselas entregado solo por el engaño perpetrado por González Carvajal con estas palabras: "dicho señor me engañó ofreciéndome, puesta la mano en el pecho y bajo palabra de honor, en que su empleo de usted no duraría muchos meses porque ya pensaba en que se suprimiera por inútip'52.

En virtud de este acuerdo, al intendente, como juez universal, justicia mayor y magistrado político con jurisdicción ordinaria, le correspondía privativamente el gobierno político de las colonias (art. 1); todo lo relativo a la Real Hacienda, especialmente en materia de pósitos y de diezmos (art. 5); y, además, acumulativamente o a prevención con el alcalde mayor, el conocimiento de todas las causas y pleitos civiles y criminales propios de la jurisdicción ordinaria (art. 2). A estos últimos también se añadirían todas las causas y pleitos sobre provisión, sucesión y traspaso de suertes, así como otros asuntos similares (art. 3). Ahora bien, a fin de evitar posibles arbitrariedades se acordó establecer un turno riguroso por el que los juzgados de la subdelegación de la intendencia y del alcalde mayor de $\mathrm{La}$ Carlota se fueran alternando las causas; para lo cual el escribano de la Subdelegación llevaría un libro registro (art. 4). El punto más importante, sin embargo, de esta concordia, precisamente el que recrudecerá aún más los conflictos de competencias en las colonias de Andalucía en los años siguientes, será el octavo. En él se deja constancia de que Sandino no se conformaba con que las facultades y prerrogativas de los subdelegados fuesen las mismas que las del intendente de La Carolina; pues, según su parecer, en aquellos solo podía recaer la de meros intendentes de rentas, por lo que la jurisdicción ordinaria y el gobierno político de las Nuevas Poblaciones de Andalucía debían quedar reunidos en su alcalde mayor. González Carvajal aceptó este punto, pero logró a cambio que, en consideración

\footnotetext{
${ }^{50}$ Hamer Flores, Adolfo, La epidemia de fiebre amarilla de 1800 y su impacto en La Carlota, capital de las Nuevas Poblaciones de Andalucia, en Trocadero. Revista de Historia Moderna y Contemporánea, 30 (2018), p. 228.

${ }^{51} \mathrm{La}$ intendencia debía de ser muy consciente de que esta real orden comunicada por la vía del ministerio de Hacienda no podía afectar a un empleo en el que los nombramientos y demás comunicaciones se realizaban por la vía de Gracia y Justicia, pero aun así aprovechó la ocasión para lanzar un golpe contra el alcalde mayor Sandino.

${ }^{52}$ Archivo Municipal de La Carolina, Jaén (en adelante AMLC), Expedientes Civiles, 2.3.8. Año 1806, doc. 1718bis.
} 
a Cadiou, el alcalde mayor conviniese en que esta concordia no se ejecutase mientras este subdelegado desempeñase dicho cargo. Por último, se dispuso que con su aprobación todos los recursos, quejas e instancias relativas a lo pactado en esta concordia, que entonces estuviesen en curso, quedarían anulados (art. 7).

Casi de inmediato, una copia de esta fue elevada al ministerio de Hacienda para su aprobación por el rey; que dispuso, por real orden de 5 de julio de ese mismo año, que esta se observase en las nuevas colonias "por abora y hasta su real determinación". O sea, recibía una aquiescencia provisional hasta que el Consejo de Castilla pudiese reunir suficientes antecedentes para resolver sobre este conflicto ${ }^{53}$. Pero las disputas no finalizaron tras este acuerdo. El alcalde mayor de La Carlota sostuvo que pocos días después de aprobar el rey la concordia, González Carvajal no dudó en violentar su artículo $8^{\circ}$ al revocar una providencia gubernativa que el subdelegado había dado con su dictamen; y no mucho después trató de convencer a Sandino para que renunciara a su escribano y despachara con el de la subdelegación, lo que escondía una clara intención de saber lo que ocurría en el juzgado ordinario con la excusa de evitar gastos supuestamente innecesarios ${ }^{54}$. Es más, el sucesor de Sandino en la vara de La Carlota, Pedro María de Sanchoyerto, interpretó ese acuerdo como una debilidad de aquel; mostrándose como el alcalde mayor más beligerante en la reivindicación de todo lo que consideraba que eran competencias propias de su cargo.

En 1807, solo unos meses después de tomar posesión de su vara, protagonizó un primer pulso con la subdelegación por la necesaria validación, según su criterio, por parte de su juzgado de todos los documentos otorgados en las nuevas colonias ante los escribanos de fechos ${ }^{55}$. Sin embargo, cuando la situación se hizo especialmente tensa, y casi insostenible en algunos momentos, fue tras la reposición del régimen foral en virtud de la real orden de 29 de julio de 1814. Joaquín Cadiou había fallecido ya por entonces, por lo que teóricamente lo dispuesto en la concordia de 1804 entraba en vigor. El alcalde mayor no se encontraba entonces en La Carlota, recayendo la jurisdicción ordinaria en el entonces contador y subdelegado interino Mariano Fernández, por lo que el nuevo intendente, Pedro Polo de Alcocer, decidió actuar con rapidez para impedirlo solicitando al ministerio de Hacienda que se procediese a anular la referida concordia. Una petición que reiteró hasta en cinco ocasiones antes de que finalizase el año, haciendo hincapié en que ese era el asunto que más urgía en las colonias pues no convenía ni siquiera cubrir la vacante en la Subdelegación sin atender antes este espinoso tema. No obstante, no solo no se anuló la concordia, sino que incluso el rey procedió por sorpresa en enero de 1815 a nombrar como subdelegado de La Carlota a uno de sus guardias de corps. En consecuencia, tras el regreso de Pedro María de Sanchoyerto de una comisión en junio de ese año ${ }^{56}$, y hasta 1824, los problemas se sucederían unos en pos de otros.

El subdelegado Manuel de Sousa, al comprobar a su llegada a las colonias de

\footnotetext{
${ }^{53}$ AHN, Fondos Contemporáneos, Gobernación, leg. 334, exp. 6.

${ }^{54}$ AMLC, Expedientes Civiles, 2.3.8. Año 1806, doc. 1718bis.

${ }^{55}$ AHN, Fondos Contemporáneos, Gobernación, leg. 334, exp. 6.

${ }^{56}$ AHN, Fondos Contemporáneos, Gobernación, leg. 332, exps. 4 y 9; leg. 296, exp. 12.
} 
Andalucía que el alcalde mayor le negaba tener las competencias de sus predecesores, argumentaba en su recurso ante el rey de 22 de abril de 1815 que eran varias las razones que evidenciaban que le correspondía a él ser la máxima autoridad en las colonias de Andalucía: en primer lugar, lo dispuesto en el Fuero de Población de 1767; en segundo lugar, su nombramiento por real decreto especial ${ }^{57}$; y finalmente, lo prevenido en la real orden de 29 de julio de 1814, que mandaba que todo en las colonias volviese al ser que tenían en 1808, es decir, a un momento en el que la concordia no estaba vigente. Por su parte, el alcalde mayor defendía la vigencia de la concordia, en virtud de la cual él poseía ya el gobierno político de las Nuevas Poblaciones de Andalucía; así como lo dispuesto en su título de nombramiento como alcalde mayor, que le concedía competencias tanto en materias civiles como criminales. Ello permitió episodios conflictivos como los ocurridos entre Sanchoyerto y los alcaldes pedáneos de La Carlota en $1816^{58}$ o los protagonizados por Sousa y el alcalde mayor en septiembre del año anterior por la venta de carne en La Carlota ${ }^{59}$. Pero entre todas estas disputas, hubo dos que destacaron especialmente: de un lado, el asunto de las escribanías, y de otro, el de

${ }^{57}$ Contamos con un testimonio bastante interesante sobre este particular. En junio de 1815, Sousa escribió a Sanchoyerto informándole de que él había tenido conocimiento de la existencia de la concordia de 1804 poco después de ser nombrado subdelegado de las Nuevas Poblaciones de Andalucía; por ello, continúa el subdelegado, "pasé a verme con el excelentísimo señor ministro de Hacienda a quien bice presente su contenido, y su excelencia me contestó: Vuestra merced está nombrado por un decreto especial de Su Majestad con las mismas facultades que obtuvo su antecesor y sin restricción alguna, y asi vuestra merced puede irse descuidado; y en el caso de que el alcalde mayor de aquellas poblaciones intente perturbar a vuestra merced en ellas, lo que no es de creer, dé vuestra merced inmediatamente cuenta a Su Majestad por mi conducto" (AHN, Fondos Contemporáneos, Gobernación, leg. 332, exp. 4).

${ }^{58} \mathrm{Al}$ parecer, los alcaldes pedáneos de esta colonia se posicionaron a favor del subdelegado en el conflicto de competencias que este sostenía entonces con el alcalde mayor Sanchoyerto, por esta razón, "les amenazó que se acordarían de ép”; y los referidos alcaldes, temiendo que cumpliese su venganza (no debemos perder de vista que mientras que los alcaldes pedáneos eran simples colonos elegidos anualmente para desempeñar un cargo de justicia, los alcaldes mayores permanecían en las colonias, al menos, por un sexenio; por lo que era bastante lógico temer represalias para cuando ya no fuesen alcaldes pedáneos), solicitaron al rey que se les admitiese la dimisión que deseaban hacer de sus cargos (AHN, Fondos Contemporáneos, Gobernación, leg. 332, exp. 4).

${ }^{59} \mathrm{~A}$ finales de agosto de 1815, Pedro María Sanchoyerto fijó un edicto en el que ordenaba que todos aquellos que quisieran echar carne en la tabla para la provisión de La Carlota, debían registrar cada ocho días los ganados en su juzgado; y que el cortador solo podría vender carne con orden suya. Ante ello, el subdelegado respondió informando al cortador de que, si obedecía esa orden, lo encarcelaría y le impondría una multa de cien ducados. Como consecuencia, el último día del mes la carnicería no abrió al no atreverse nadie a llevar carne por temor a ser castigados por una de las dos autoridades. El alcalde mayor trató de atajar la situación ordenando el 1 de septiembre que se descerrajase la puerta de la carnicería y localizando él mismo una res para surtir al pueblo. Y esto fue lo que se hizo, fijándose además en la puerta de este establecimiento un papel para que nadie reconociese en Sousa autoridad alguna. Este, nada más enterarse, acudió también a la carnicería para retirar dicho bando; pero Sanchoyerto, cogiéndolo del brazo, lo sacó a la fuerza de la carnicería. Ya en el exterior, ambos mantuvieron una enconada discusión -en el transcurso de la cual, Sousa rasgó el bando-, que solo acabó cuando el alcalde mayor decidió retirarse para dejar de oír los gritos y expresiones de apoyo al subdelegado que lanzaban los colonos que se habían ido concentrando en torno a ellos (AHN, Fondos Contemporáneos, Gobernación, leg. 332, exp. 4). 
la asesoría de la subdelegación; sin embargo, no nos ocuparemos de ellas ahora, ya que su importancia nos ha hecho considerar conveniente abordarlos somera pero individualizadamente. Del mismo modo, también trataremos monográficamente el conflicto más destacado entre los ocurridos en las colonias de Sierra Morena: el asunto de la correspondencia dirigida a la justicia de La Carolina.

En otro orden de cosas, todos estos problemas también se trasladaron entonces a los vecinos de las colonias. La mayor parte, ciertamente, apoyaban al subdelegado $^{60}$, circunstancia que llevaría a Sanchoyerto, si hacemos caso de los testimonios de numerosos colonos, a cometer abusos y excesos contra ellos. Un ejemplo bastante elocuente lo tenemos en lo que le ocurrió a un colono de La Fuencubierta, aldea ubicada en la feligresía de La Carlota, en 1818. Carlos Sanz, que así se llamaba, no formaba parte del grupo de colonos afectos en aquella aldea al alcalde mayor, por lo que aquellos planearon un ataque contra él. Aprovechando que algunas de sus reses vacunas se habían introducido, aunque apenas causaron daños, en la suerte de Jacobo Jiménez, consiguieron convencer a este último para que denunciara a Sanz. De resultas de ello, se le condenó en el juzgado ordinario a abonar treinta reales de vellón por cada res introducida, así como a pagar los mil reales a que ascendieron las costas procesales. Cantidad que debía abonar en un plazo máximo de tres días, o en caso contrario sufriría el embargo de sus bienes y sería encarcelado. Con no pocas dificultades, Sanz pudo reunir esta considerable cifra; por lo que difícilmente podría hacer frente a un nuevo lance de los denunciadores. Ello fue lo que le llevó a mediados de septiembre de ese año a elevar una súplica a Fernando VII pidiendo que le protegiese de estos abusos ${ }^{61}$.

A pesar de que el rey por sucesivas reales órdenes, como la de 1 de julio de 1804, 6 de enero y 6 de junio de 1815, había dispuesto que el Consejo de Castilla instruyese un expediente para evacuar una consulta a fin de cortar las desavenencias entre la intendencia y los alcaldes mayores de La Carolina y La Carlota ${ }^{62}$; este nunca lo concluyó. Los conflictos no finalizaron hasta finales de 1824, fecha en la que no se accedió a que Sanchoyerto volviera a ejercer la vara de La Carlota. La llegada del sistema constitucional en marzo de 1820 había interrumpido su sexenio, que llegaba hasta 9 de junio de 1821, por lo que, una vez finalizado el Trienio Constitucional y expulsado de su destino como juez de primera instancia del partido de Antequera, consideró seriamente el recuperar el destino anterior. Sus vínculos con la capital de las colonias de Andalucía no se habían roto, ya que sus hermanas continuaron residiendo allí, por lo que se trasladó inmediatamente a La Carlota y solicitó al rey ser repuesto en su antigua vara el 24 de octubre de 1823; petición que trasladó el 11 de diciembre a la Chancillería de Granada. Esta última, sin perjuicio de lo que resultase de la correspondiente purificación, acordó su reposición y se libró despacho el 20 de diciembre para que volviera a ocupar su

\footnotetext{
${ }^{60}$ Aunque no nos han llegado muchas, las quejas elevadas por numerosos colonos de las distintas feligresías contra el alcalde mayor de La Carlota muestran bastante bien que el mal carácter y los oscuros procedimientos de Sanchoyerto no despertaban en ellas muchas simpatías precisamente (AHN, Fondos Contemporáneos, Gobernación, leg. 332, exp. 4).

${ }^{61} \mathrm{AHN}$, Fondos Contemporáneos, Gobernación leg. 280, exp. 18.

${ }^{62}$ AHN, Fondos Contemporáneos, Gobernación, leg. 334, exp. 21.
} 
alcaldía mayor. Sanchoyerto, una vez logrado su objetivo, requirió al subdelegado Manuel de Sousa el cumplimiento de lo que disponía ese despacho, pero este se negó a hacerlo; en su lugar, unos días más tarde, le comunicó un decreto del intendente Polo de Alcocer fechado en 3 de enero de 1824. Sousa, que ya desde septiembre había hecho gestiones por si aquel mostrara interés por volver a su $\operatorname{vara}^{63}$, había escrito al intendente el 31 de diciembre informándole de la novedad y este último, argumentando haber provocado un tumulto en la colonia en marzo de 1820 y ser responsable de un "delito de traición a la autoridad de su majestad", dispuso que le hiciera salir de las colonias en el término de veinticuatro horas y, de no hacerlo, lo arrestase y llevase a la cárcel. El subdelegado cumplió esta disposición por auto fechado en 8 de enero en el que dispuso que no había lugar a la reposición y concediendo el plazo referido para que abandonase la jurisdicción.

Comenzó entonces una escalada de cartas y recursos que finalizó con la resolución real de 11 de octubre de 1824, la cual se inclinó a favor de Sanchoyerto tras el acuerdo de la Real Chancillería de Granada de 7 de julio y del dictamen del fiscal de la Cámara de Castilla de 7 de septiembre en este mismo sentido. Se negaba, pues, la veracidad de las acusaciones que desde la intendencia de Nuevas Poblaciones se habían realizado contra él, pero habida cuenta del largo enfrentamiento se consideró más beneficioso el que se le tuviera presente para otra vara; siendo nombrado alcalde mayor primero de la Ciudad de Córdoba en junio de $1826^{64}$. La vara de La Carlota permaneció vacante hasta 1825, momento a partir del cual los alcaldes mayores que la ocuparon, al parecer, no volverían a mantener este tipo de enfrentamientos con la intendencia y su subdelegación ${ }^{65}$. Sirva como ejemplo que Justo Rodríguez Hurtado de Bruna, al solicitar el 22 de junio de 1825 una licencia para pasar a Granada y otros pueblos de su territorio a resolver asuntos particulares, no dude en afirmar "que no siendo actualmente en esta [La Carlota] muy precisa su personalidad, por haber aqui intendente honorario de provincia subdelegado gobernador de estas poblaciones de Andalucía". De todos modos, en honor a la verdad, debemos reconocer que la desaparición de estos conflictos en los últimos años del régimen foral se explica más por la negativa a pleitear de los últimos alcaldes mayores, algunos por cierto con bastantes problemas de salud ${ }^{66}$, y no por una intervención contundente de la administración central.

${ }^{63}$ El 24 de septiembre de 1823, sin mediar orden de ninguna autoridad superior, había oficiado al concejo de Antequera a fin de obtener un informe de la conducta de Sanchoyerto durante el periodo que ejerció como juez de primera instancia. En dicho informe, expedido el 1 de octubre, se manifestaba que aquel siempre había sido considerado en la localidad como un constitucionalista exaltado.

${ }^{64}$ AHN, Consejos, leg. 13263, exp. 68. Bernardo Ares, José Manuel, cit. (n. 25), pp. 47-48.

${ }^{65} \mathrm{El}$ intendente Polo de Alcocer manifestaba a finales de 1825 que las antiguas guerras que sostuvo con los alcaldes mayores ya habían concluido (AHN, Fondos Contemporáneos, Gobernación, leg. 387, exp. 5).

${ }^{66} \mathrm{ARChG}$, cabina 321, leg. 4309, pieza 4. Estos problemas de salud nos constan, al menos, en los casos de Justo Rodríguez Hurtado de Bruna y de Miguel Rodríguez Fuentes (Boletín Oficial de la Provincia de Córdoba, 3 de abril de 1835). 


\section{III. "HACER GUERRA A LA INTENDENCIA": LAS CUESTIONES DE MAYOR GRAVEDAD}

La retórica habitual en las instancias al gobierno de exagerar para así lograr los objetivos deseados podría hacernos pensar que la situación no fue, en realidad, tan grave en las colonias. El objetivo, por tanto, de este apartado será el de mostrar los episodios de mayor gravedad entre aquellos de los que nos ha llegado información suficiente. Como ya hemos tenido ocasión de manifestar, en las colonias de Sierra Morena los problemas fueron puntuales, lo que no impidió que en la etapa del alcalde mayor José Francisco Flores Villamil, justo en los inicios de la intendencia de Pedro Polo de Alcocer, toda la jurisdicción de las nuevas colonias se viera afectada por ellos. En esa lucha competencial destacó un tema tan sensible como el derecho de recepción y apertura del correo destinado al corregidor y justicia de La Carolina. Ahora bien, fueron las colonias de Andalucía las que mejor evidenciaron estos enfrentamientos. Todo aquello que no fueran cuestiones de la Real Hacienda o estrictamente criminales estaban en disputa y tanto el subdelegado como el alcalde mayor las reivindicaban como de su competencia, negando la legitimidad del otro para intervenir en ellas. El resultado fue un entorpecimiento constante en muchos ámbitos, ralentizándolos y causando perjuicio, en último término, a la población. Entre ellos, destacaron algunos por su gravedad y duración en el tiempo, haciendo forzosa la intervención del gobierno: la cuestión de los escribanos y la de la asesoría de la subdelegación.

\section{La correspondencia sobre justicia recibida en La Carolina}

Si la distribución de competencias no quedaba clara ni dentro de las nuevas colonias, de ahí que se disputase, podemos imaginar la confusión que las autoridades de otros lugares pudieron llegar a tener a la hora de comunicarse con sus autoridades y cargos de justicia. Una circunstancia que llevaba a que en muchas ocasiones el intendente o sus subdelegados abriesen la correspondencia dirigida a los alcaldes mayores, teniendo acceso a informaciones que comprometían tanto las actuaciones de la justicia ordinaria como la necesaria confidencialidad de las comunicaciones que aquellos mantenían. De ahí que, cansado de este hecho, el titular de la vara de La Carolina recurriese a la Dirección General de Correos en enero de 1815 para que todos los pliegos que llegasen a la estafeta de La Carolina dirigidos "Al corregidor o justicia de La Carolina" se le entregasen a él y no al intendente, logrando que se diese orden el día 20 de ese mes para que desde entonces se procediese de ese modo. Una decisión que Polo de Alcocer trató de revertir lo antes posible, logrando que la secretaría de Estado, el 12 de mayo, devolviese todo a la situación previa; desmarcándose de este conflicto, por no tener competencias para decidir, y conminando al intendente y alcalde mayor a que dirimiesen sus conflictos por la vía que correspondiese.

Mientras tanto, las gestiones de José Francisco Flores Villamil ${ }^{67}$ habían logrado

${ }^{67}$ Flores Villamil ejerció como juez de primera instancia de La Carolina desde el 20 de enero de 1813, pasando a desempeñar el cargo de alcalde mayor cuando se restableció el sistema foral. Su enfrentamiento con Polo de Alcocer comenzó, según parece, cuando comprobó que el proceso de depuración de empleados realizado en 1814 no contó con todas las garantías necesarias. 
que la secretaría de Gracia y Justicia obtuviese una real orden, el 4 de mayo, en la que el monarca disponía que la correspondencia de oficio dirigida al corregidor o justicia de La Carolina debía entregarse a quien ejerciera la real jurisdicción ordinaria; comunicándosele al alcalde mayor pero, al parecer, no al intendente, por lo que Flores Villamil recurrió nuevamente al ministro de Gracia y Justicia el 28 de mayo. En esta ocasión sí hubo más suerte, pues los directores generales de Correos escribieron el 14 de julio a Polo de Alcocer para que se trasladase la real orden de 4 de mayo al encargado de la estafeta de La Carolina. Este nuevo revés obligó al intendente a oficiar al ministro de Hacienda el mismo día que recibió la carta para indicarle que consideraba imprescindible que se gestionase la anulación de esa orden, ya que no podía consentir que el alcalde mayor accediera a materias de gobierno que esa correspondencia regularmente contenía. Reivindicaba en su misiva que, como intendente, era "gobernador, juez universal y justicia mayor de las colonias"; correspondiéndole "todo lo civil perteneciente a la dirección de la empresa, con el gobierno y con todas las funciones que corresponderian a los ayuntamientos si los hubiese" ${ }^{\text {" }}$. No tenemos datos de cómo finalizó esta cuestión, pero el hecho de que no existan menciones posteriores a este conflicto nos pone en la pista de que debió de resolverse a favor de la intendencia.

\section{La cuestión de los escribanos de fechos en las colonias de Andalucía}

El conflicto que mantuvieron la intendencia y el alcalde mayor de La Carlota por la cuestión de los escribanos es quizá uno de los más interesantes de cuantos hubo, pero tan complejo y extenso que aquí solo podremos ofrecer unas pinceladas. Ambas partes se mostraron muy interesadas en tener información sobre lo que se manejaba en el juzgado de la otra; y una buena manera de conseguirlo era logrando que un único individuo, obviamente tanto uno como otro aspiraban a que fuera su escribano, se ocupara de las dos escribanías de la capital de las colonias de Andalucía. En 1802, Juan Vázquez, que había actuado como escribano real único de los juzgados de la Subdelegación y del alcalde mayor de La Carlota desde la época de la superintendencia ${ }^{69}$, cesó voluntariamente en su cargo. De resultas de ello, González Carvajal estimó conveniente que los asuntos se distribuyeran entre dos escribanos o fieles de fechos, uno para cada juzgado. Así, el 19 de junio de 1802 nombró a Miguel Muñoz como escribano de la subdelegación y a José María Custodio como escribano del juzgado del alcalde mayor. Sin embargo, pronto se consideró inadecuado que el juzgado de la subdelegación fuese atendido por un simple fechero, por lo que se solicitaría al rey su nombramiento como notario de reinos, título que se le expediría el 5 de octubre de 1804 con la obligación de residir en La Carlota. No obstante, y a pesar de que el intendente trató de evitarlo, también el alcalde mayor aspiraba a que su escribano de fechos fuera nombrado escribano de reinos, sobre todo porque si ello no ocurría este pasaría a

Esto hizo posible que claros colaboracionistas con el régimen francés no solo fuera rehabilitados sin ningún problema, sino que incluso accedieran a destacados puestos por decisión del nuevo intendente (AHN, Fondos Contemporáneos, Gobernación, leg. 332, exp. 4; y leg. 334, exp. 15).

${ }^{68}$ AHN, Fondos Contemporáneos, Gobernación, leg. 334, exp. 20.

${ }^{69} \mathrm{AHN}$, Consejos, leg. 27194, exp. 6. 
depender de Muñoz; y finalmente lo consiguió, expidiéndosele a Custodio el real título el 12 de octubre de ese mismo año con la misma obligación de residencia ${ }^{70}$. La respuesta de la intendencia no se dejaría esperar demasiado. Conscientes de que al haber dos escribanos de reinos no sería posible tener control sobre el que ejercía sus funciones en el juzgado ordinario, y menos aún conocer los asuntos que se trataban en este, González Carvajal recurrió el nombramiento, tratando de demostrar que Custodio no reunía los requisitos para ejercer esta función, pero la sala de Justicia del Consejo de Castilla sentenció a favor del escribano en noviembre de 1804. Se inició entonces un largo conflicto que se extendió hasta 1819 y cuya primera acción correspondió al intendente, que se negó a pagar su sueldo a Custodio, al haber concedido íntegro el de Vázquez a Muñoz a pesar de que este no actuaría en el juzgado ordinario ${ }^{71}$.

\section{El asunto de la asesoría de la subdelegación de La Carlota}

La Ordenanza de intendentes de 1749 dispuso que los alcaldes mayores fueran asesores ordinarios del intendente-corregidor, el cual no podría acudir a otros individuos para este cometido. Una disposición aliviada mediante la real orden de 10 de marzo de 1764, que autorizaba a los intendentes y sus subdelegados a poder elegir un hombre "de su satisfacción" como asesor si ello fuera necesario ${ }^{72}$. Un recurso al que hábilmente recurrió, en 1816, la intendencia de Nuevas Poblaciones para intentar contener al alcalde mayor y, de paso, privarle de un tercio de su salario. La negativa de Pedro María Sanchoyerto a asesorar al subdelegado en unos autos que el primero consideraba que eran competencia de su juzgado en virtud de la concordia de 1804, llevó a que se le suspendiese de empleo y sueldo como asesor a partir del 25 de enero de 1816; nombrando interinamente en su lugar al licenciado Miguel Escribano Luque, abogado de los Reales Consejos. Todavía más, Pedro Polo de Alcocer no dudó en proponer a este último para que se le concediese en propiedad la asesoría de la subdelegación de La Carlota con la dotación que para esta labor habían venido recibiendo los alcaldes mayores, con lo que Sanchoyerto solo mantendría las causas criminales que llegasen a su juzgado y una consignación anual de 400 ducados. El alcalde mayor tampoco dilató demasiado su queja por el agravio, sin fundamento desde su óptica, que había sufrido al retirársele las funciones y sueldo de asesor de la subdelegación; un destino que consideraba propio e inherente a las atribuciones de su vara. Fernando VII resolvió esta cuestión de un modo bastante salomónico en su real orden de 2 de noviembre de ese mismo año: de un lado, confirmó que esa asesoría correspondía a los alcaldes mayores, reintegrándolo en ella, y de otro, rechazó la petición de este para cobrar su sueldo durante el tiempo que se le privó de esta, pues se había negado a ejercer las funciones de asesor a pesar de las reiteradas órdenes que le comunicó la intendencia ${ }^{73}$.

\footnotetext{
${ }^{70}$ ARChG, cabina 321, leg. 4355, pieza 33.

${ }^{71}$ AMLC, Expedientes Civiles, 2.3.8. Año 1806, doc. 1718bis.

${ }^{72}$ Novísima Recopilación, libro VII, título XI, ley 25.

${ }^{73}$ AHN, Fondos Contemporáneos, Gobernación, leg. 332, exp. 9.
} 


\section{REDUCIR LOS CONFLICTOS: LA INTERVENCIÓN DE LOS INTENDENTES DE LAS}

Nuevas Poblaciones en el nOmbramiento de los alCaldes mayores

La implantación de unos alcaldes mayores con una vía de nombramiento alejada de la habitual para los cargos que actuaban en las nuevas colonias, la de la secretaría de Estado y del Despacho de Hacienda, con unos títulos cuya redacción, además, no se ajustaba a sus particularidades de gobierno, no dejó impasible a la intendencia. Desde un primer momento, se combinaron las peticiones a Madrid de sus gobernantes para resolver esa anomalía con otras intervenciones indirectas que, al menos, permitieran solicitar prórrogas de aquellos alcaldes mayores que hubieran actuado sin generar tensiones y sugerir posibles candidatos para cubrir las vacantes en estas varas. Se trataba, en verdad, de unas solicitudes o propuestas que la secretaría de Hacienda trasladaba a la de Gracia y Justicia simplemente como sugerencias, pero lo cierto es que en no pocas ocasiones el deseo de facilitar la buena marcha de las Nuevas Poblaciones, ya que esos alcaldes mayores también actuaban, como acabamos de ver, como asesores de su intendencia, permitió que fueran tenidas muy en cuenta. En este sentido, podemos hablar de éxitos tan llamativos como la permanencia de un alcalde mayor en las colonias de Sierra Morena durante más de dos décadas, en las que, como puede suponerse, se mantuvo alejado el fantasma de los conflictos de competencias.

Las lagunas documentales ${ }^{74}$, así como la compleja localización de los testimonios que puedan conservarse sobre esta cuestión, no permiten tener una visión integral de todas las solicitudes e informes realizados, pero consideramos que los ejemplos que expondremos dan buena cuenta de este modo de proceder. El subdelegado de las Nuevas Poblaciones de Sierra Morena elevó el 6 de septiembre de 1782, por la vía reservada de Hacienda, una instancia dirigida al rey en la que le daba cuenta de que el trienio de Manuel Fernández de Nalda como alcalde mayor en esas colonias estaba próximo a finalizar ${ }^{75}$, proponiendo que esa vacante recayera en Antonio María Lomas. Frente al primero, que había tenido "poca utilidad para fomento de aquellos establecimientos", consideraba que Lomas sería mucho más útil por haber actuado ya satisfactoriamente como defensor de los intereses de esas nuevas colonias ante otras instancias y por ser un "abogado de mucho crédito establecido en la ciudad de Úbeda”. Carlos III ordenó que esta representación pasase a la secretaría de Gracia y Justicia para que la Cámara de Castilla lo tuviera presente al cubrir la vacante, pero la suspensión que se hizo en todo el reino de esas provisiones para poner en marcha la nueva planta que entró en vigor el 1 de octubre de 1783,

\footnotetext{
${ }^{74}$ La mayor parte de la correspondencia cruzada entre la intendencia de las Nuevas Poblaciones y la secretaría de Estado y del Despacho de Hacienda con posterioridad al año 1799 desapareció en el incendio que arrasó por completo en 1939 el Archivo General Central de Alcalá de Henares (Madrid), ya que solo se habían transferido al Archivo General de Simancas (Valladolid) los legajos anteriores a 1800; quedando pendientes los restantes por falta de espacio en los depósitos de este último.

${ }^{75}$ Manuel Fernández de Nalda fue nombrado por el rey para ejercer durante un trienio la vara de La Carolina en el mes julio de 1779. Véase Mercurio Histórico y Político que contiene el estado presente de la Europa, lo sucedido en todas las cortes, los intereses de los principes y generalmente todo lo más curioso, perteneciente al mes de julio de 1779 (Madrid, Imprenta Real de la Gazeta, 1779), p. 291.
} 
frustró las esperanzas de Ondeano. El hecho de que esa nueva planta estuviera elaborada previamente, aunque no publicada, hizo que el designado para la alcaldía mayor de La Carolina fuera Francisco Vicente Fernández.

No obstante, sus problemas judiciales, pues tenía abierta una causa criminal y estaba encarcelado en Madrid por orden de la Sala de Alcaldes, impidieron que pudiera tomar posesión de la vara; al menos mientras no se dictara una sentencia que lo hiciera factible. Una situación que causaba no pocos perjuicios en las colonias, pues los asuntos pendientes se acumulaban, de ahí que el subdelegado acudiese el 26 de marzo de 1784 al presidente del Consejo de Castilla, Pedro Rodríguez de Campomanes, para que se nombrase interinamente a Lomas mientras tanto; logrando que este tomase posesión el 18 de abril. La sentencia de la Sala de Alcaldes sobre la causa de Fernández llegó en julio de 1786, condenándolo con la suspensión de poder ejercer durante cuatro años jurisdicción, lo cual fue confirmado en mayo del año siguiente tras el recurso que este interpuso. Lomas pudo, por tanto, continuar su desempeño en la vara de manera interina hasta que, en mayo de 1791, la posibilidad de que se proveyese la vacante animó al intendente a solicitar al rey que o bien se declarase la propiedad de esta vara en Lomas o bien se suspendiese la consulta de la Cámara de Castilla hasta que las nuevas colonias estuviesen finalizadas, pudiendo seguir en ella de forma interina el tiempo necesario ${ }^{76}$. Apoyaba su súplica en dos argumentos principales: de un lado, en que no convenía el nombramiento en este territorio de alguien que empezara su carrera, como solía ocurrir por ser de primera clase ${ }^{77}$, cuando se disponía para ello de un individuo que había demostrado su valía durante siete años y, de otro lado, en el intachable desempeño de la jurisdicción ordinaria por parte de Lomas en ese tiempo, pues afirma que la había servido "con amor a ella, con talento no común y justificación, [y] bien penetrado de las ideas con que se dirigen, gobiernan y fomentan estas Nuevas Poblaciones". La petición encontró en Carlos IV una acogida favorable al mostrarse conforme con la segunda opción, de ahí que dispusiese el día 21 de ese mismo mes que la Cámara no consultara la provisión de esa vara mientras que él no ordenase otra $\operatorname{cosa}^{78}$.

Algunos años más tarde el asunto de la provisión de esta vara se reactivó de nuevo. Una real orden fechada el 26 de octubre de 1798 resolvió que Antonio Lomas fuera consultado para una vara de tercero y último ascenso, lo cual implicaba una importante promoción en su carrera. Tal vez su deseo de no alejarse demasiado de la región en la que había nacido y vivido la mayor parte de su vida, lo animó a solicitar el corregimiento vacante de Linares, que se ajustaba al nivel

\footnotetext{
${ }^{76}$ Esta petición, que contravenía abiertamente los principios básicos que habían inspirado el propio Fuero de Población de 1767, da buena cuenta de la envergadura del problema con los alcaldes mayores. Una vez localizado uno con el que existía buena relación y no se disputaban cuestiones de competencias, no se dudó en intentar que permaneciese el mayor tiempo posible por la vía de la propiedad vitalicia del empleo o de una interinidad de larga duración.

${ }^{77}$ Las alcaldías mayores se dividieron en tres clases en 1784, siendo las de primera entrada aquellas que menores ingresos proporcionaban a sus titulares, al no llegar a los mil ducados de vellón anuales (Novísima Recopilación, libro VII, título XI, ley 29, art. 1).

${ }^{78}$ AGS, Secretaria y Superintendencia de Hacienda, leg. 502, docs. 30 y 34.
} 
concedido. El intendente González Carvajal, como no podía ser de otro modo, la respaldó elogiándolo como "uno de los mejores letrados que andan en la carrera" y sosteniendo que, aunque con su marcha le habría de "hacer mucha falta" en La Carolina, le quedaba el consuelo de que la proximidad de Linares haría posible poder acudir a Lomas cuando la relevancia de los asuntos lo requiriera; incluso no dudó en solicitar un incremento en el salario que recibiría en ese destino por estar la vara de Linares entre las menos dotadas de las de tercer clase ${ }^{79}$. Desconocemos las razones que llevaron a paralizar esta provisión, tal vez tuvo efecto alguna súplica del intendente que no hemos podido localizar, pero lo cierto es que Lomas todavía pudo continuar algunos años más desempeñando esta vara. Su marcha tuvo que esperar finalmente a un momento que no podemos precisar entre $1804^{80}$ y $1806^{81}$, siendo entonces reemplazado por José María de Otero de Figueroa. Es probable que este último fuera el alcalde mayor fallecido en el verano de 1809 del que nos informa el intendente Hermenegildo Llanderal ${ }^{82}$ en la última recomendación que nos consta para estas colonias, cuando se dirigió al gobierno para suplicar que esa vacante se cubriese con Manuel Antonio Romero ${ }^{83}$.

En lo que respecta a las Nuevas Poblaciones de Andalucía, tan solo hemos podido localizar un ejemplo. Estando próxima a vacar la vara de La Carlota, el intendente Miguel Ondeano representó al rey, por la vía de Hacienda, el 7 de agosto de 1791 al objeto de indicar los rasgos que debían concurrir en el individuo que la ocupase, pues conocía la "importancia de aquella elección para servir aquella vara, $y$ [deseaba] reparar que recaiga por acaso en letrado que, poco instruido tal vez. del sistema particular de gobierno de las Nuevas Poblaciones, pueda embarazar y atrasar el fomento y adelantamiento de aquellos establecimientos"; recomendando al abogado de los Reales Consejos Fernando Ximénez de Alba y Villalón, natural de la cercana localidad de Fernán Núñez, afecto a la empresa colonizadora y con caudal suficiente como para no buscar beneficios excesivos en este juzgado. Una propuesta que reiteró a comienzos del mes de diciembre, insistiendo en la necesidad de que el elegido no se dedicase a abrir autos por todo buscando beneficio, pues la práctica habitual en las colonias era resolver con juicios orales los problemas y así evitar que las haciendas de sus vecinos se resintieran con costas excesivas. El ministerio de Hacienda accedió a realizar esta recomendación al de Gracia y Justicia, formalizándola el 30 de marzo del año siguiente ${ }^{84}$; aunque sin lograr el éxito esperado, pues la vara recayó en Francisco de Paula Padial, que mantuvo no pocos enfrentamientos con la Intendencia y su subdelegación, al menos en los primeros años de su sexenio ${ }^{85}$.

${ }^{79}$ AGS, Secretaría y Superintendencia de Hacienda, leg. 503, doc. 233.

${ }^{80}$ Señán y VelázQuez, Joseph, Guía o estado general de la Real Hacienda de España. Parte primera. Año de 1804 (Madrid, Imprenta de Vega y Compañía, 1804), p. 197.

${ }^{81}$ En este año ya ocupaba José María de Otero de Figueroa la vara de las Nuevas Poblaciones de Sierra Morena: Señán y Velázquez, Joseph, Guía o estado general de la Real Hacienda de España. Año de 1806 (Madrid, Imprenta de Vega y Compañía, 1806), p. 283.

${ }^{82}$ Intendente de las Nuevas Poblaciones de Sierra Morena y Andalucía entre 1807 y 1810.

${ }^{83} \mathrm{AHN}$, Consejos, leg. 11992, exp. 2. Carta de Francisco de Saavedra al decano del Consejo Supremo de España e Indias.

${ }^{84}$ AGS, Secretaría y Superintendencia de Hacienda, leg. 502, doc. 31, 33 y 107.

${ }^{85}$ AHN, Consejos, leg. 4059, exp. 5. 
En otro orden de cosas, hubo otra circunstancia que también ayudó a reducir las tensiones: el propio interés de algunos alcaldes mayores, que sabían que su destino tendría una duración determinada, de ejercer sus funciones con la mayor tranquilidad posible y, además, ganándose el favor de los dirigentes neopoblacionales para que con sus recomendaciones se facilitase su carrera profesional. No puede perderse de vista que al ser varas de primera clase sus titulares desearían promocionar a otras de mayor importancia y remuneración, por lo que entablar pleitos con la Intendencia podía limitar bastante las opciones. Los alcaldes mayores permanecían en sus varas solo tres años, seis a partir de la reforma de 29 de marzo de $1783^{86}$, por lo que esa recomendación era un activo muy interesante a su favor. Disponemos de un par de ejemplos en este sentido. Ante la inminente finalización, el 19 de julio de 1777, del trienio que debía ejercer la vara de La Carolina el alcalde mayor Luis de Herrera y Román, Ondeano solicitó al gobierno el 24 de junio que, aunque este quería retirarse, se suspendiese la provisión de la plaza y que continuase en ella hasta resolver los asuntos que tenía pendientes; a lo que el rey accedió por real orden de 26 de noviembre. Del mismo modo, también solicitó entonces que, por sus méritos, se le incrementase el salario de 800 ducados anuales por considerarlo insuficiente al tener que mantener dos caballos para los asuntos que debía atender. La Cámara de Castilla convino en que no eran suficientes, pero desconocemos si efectivamente se incrementó esa cantidad. Menor fortuna tuvo el propio Herrera pues, tras acudir a Ondeano y al marqués de los Llanos, regente de la Audiencia de Sevilla, que realizó una visita a las colonias de Sierra Morena a finales de 1777, pidiendo alguna distinción honorífica por sus méritos, el monarca no tuvo a bien concedérsela en su resolución de 17 de mayo de $1778^{87}$. Por otro lado, cuando en 1798 el ya mencionado alcalde mayor Francisco de Paula Padial, que finalizaba su sexenio en La Carlota elevó un memorial al ministro de Hacienda, el sevillano Francisco Arias de Saavedra, solicitando su ascenso a una vara de segunda clase, logró que el intendente González Carvajal, a pesar de los conflictos que aquel mantuvo con su predecesor, avalase su petición afirmando el 16 de junio que tenía "noticias de que ha procedido con pureza y desinterés en aquel destino", de ahí que Padial lograse que el ministerio de Hacienda recomendase su solicitud al de Gracia y Justicia el 29 de junio ${ }^{88}$.

\section{CONCLUSiones}

Una vez analizados en los apartados anteriores los principales aspectos del tema que aquí nos ocupa, consideramos que es el momento de verificar si se han alcanzado los objetivos marcados en esta investigación y de ofrecer las principales conclusiones obtenidas. En lo que respecta a los objetivos, pensamos que hemos cumplido de manera satisfactoria nuestro propósito de conocer el contexto en el que nacieron, en 1770, las alcaldías mayores dentro de la jurisdicción de las

\footnotetext{
${ }^{86}$ Novísima Recopilación, libro VII, título XI, ley 29, art. 4.

${ }^{87}$ AGS, Secretaría y Superintendencia de Hacienda, leg. 499, docs. 123; AHN, Fondos Contemporáneos, Gobernación, leg. 279, exp. 23.

${ }^{88}$ AGS, Secretaría y Superintendencia de Hacienda, leg. 503, docs. 218, 219 y 220.
} 
Nuevas Poblaciones de Sierra Morena y Andalucía, al igual que los conflictos que tuvieron lugar durante décadas entre la intendencia de estas últimas y aquellas por el teórico solapamiento de atribuciones. El gobierno nunca dio una respuesta clara a estos últimos, limitándose a intervenciones puntuales cuando los asuntos adquirían notable gravedad. Evidenciamos, pues, un ejemplo de cómo la administración borbónica, a pesar de la voluntad centralizadora del siglo XVIII, mostró desinterés, tal vez incluso incapacidad, para resolver una cuestión muy simple y que solo habría requerido una orden del rey. Al tratarse de un asunto que afectaba únicamente a un territorio con una jurisdicción especial, esa necesaria delimitación de competencias no hubiera afectado a las que esos mismos empleos tenían en otros lugares de la Corona; si es que éste hubiera podido ser el temor que albergasen algunos individuos. Habría sido tan simple como que el Consejo y Cámara de Castilla hubieran alcanzado una postura común con las secretarías de Hacienda y de Gracia y Justicia, pero parece que el impulso reformista con el que nacieron las nuevas poblaciones se había diluido ya por completo solo unos años más tarde. Las consecuencias de haber cronificado un problema que tenía fácil solución, como no podía ser de otro modo, afectaron bastante al devenir y prosperidad de estas nuevas colonias; no solo por el tiempo y esfuerzo que se emplearon en enfrentamientos casi constantes, que paralizaban no pocas decisiones en espera de la resolución del rey, sino también por el ambiente enrarecido que causaron entre los gobernados al verse obligados, muchas veces, a posicionarse a favor de una u otra autoridad, con todo lo que ello implicaba posteriormente en sus relaciones con la otra parte.

Como principales conclusiones, podemos concretar, en primer lugar, que el establecimiento de las alcaldías mayores en las Nuevas Poblaciones de Sierra Morena y Andalucía se produjo, en octubre de 1770, en un contexto peculiar (el de la visita de inspección realizada por el jurista Pedro José Pérez Valiente y sus consecuencias), en el que no hubo mucha preocupación por insertar estas varas adecuadamente en el organigrama de atribuciones y competencias que regulaba para aquellas el Fuero de Población de 1767. Así pues, se dio origen a una delicada situación en la que, en teoría, intendentes y alcaldes mayores podían entender como máxima autoridad en asuntos de carácter civil, apoyándose los primeros en el Fuero y los segundos en su nombramiento; pero ni los unos ni los otros reconocían esas atribuciones en el contrario. Los enfrentamientos, por tanto, no tardarían mucho en llegar. El partido territorial de las Nuevas Poblaciones de Sierra Morena, al residir allí la mayor parte del tiempo el intendente, los vivió con menos intensidad que el partido de las Nuevas Poblaciones de Andalucía, donde la máxima autoridad, en ausencia de dicho intendente, era un subdelegado.

Esto nos lleva a nuestra segunda conclusión. Los alcaldes mayores de La Carolina mantuvieron, por lo general, una actitud colaborativa con la intendencia, facilitada por el nombramiento y prórrogas en el cargo de algunos individuos recomendados por esta debido a que tenían un perfil que evitaba los conflictos; de ahí que las etapas de enfrentamiento y relaciones tensas fueran escasas durante todo el periodo foral. No ocurrió lo mismo con varios alcaldes mayores que ocuparon la vara de La Carlota, lo cual tuvo su reflejo en una larga etapa que los coetáneos no dudaron en calificar incluso de guerra y que se extendería, al me- 
nos, desde 1789 hasta 1824. Con la transformación de la superintendencia de las Nuevas Poblaciones en intendencia a partir de 1784, que hizo que en las colonias de Andalucía la máxima autoridad dejase de ser un subdelegado con graduación de intendente de provincia, los alcaldes mayores de este partido empezaron a cuestionar no solo las competencias del intendente, al entender que no distaban mucho de las que tenía cualquier otro de los nombrados en la Península, sino sobre todo las de su subdelegado en La Carlota. Este último era visto solo como un mero subdelegado de rentas, por lo que incluso en el caso de reconocer que el intendente fuese el justicia mayor en esta jurisdicción, no podía este reemplazarlo por completo cuando estuviera ausente. El alcalde mayor, en este caso, asumiría buena parte de dichas atribuciones, exceptuando los temas de hacienda y fomento. Así pues, algunos de ellos como Francisco de Paula Padial, Ignacio Pablo Sandino de Castro y, sobre todo, Pedro María de Sanchoyerto disputaron abiertamente con la intendencia las atribuciones que argumentaban poseer; dando origen a varios enfrentamientos relevantes, como los que afectaron a los escribanos de fechos y al desempeño de la asesoría de la subdelegación. Este convulso panorama, que, como decíamos, dificultaba las propias tareas de gobierno, llevó al intendente Tomás José González Carvajal a intentar calmar las aguas a comienzos del siglo XIX con la firma de una concordia entre la intendencia y la alcaldía mayor de La Carlota, ocupada entonces por Sandino. Tras una compleja negociación de varios años, en mayo de 1804, se suscribía en esa capital un documento que teóricamente ponía fin a todos los litigios previos y clarificaba, mientras el rey resolvía sobre el fondo de este problema, las atribuciones de subdelegados y alcaldes mayores en las colonias de Andalucía. Aunque el monarca dio su visto bueno pocas semanas después a la concordia, lo cierto es que las cesiones que realizaron ambas partes para llegar a ese acuerdo fueron rechazadas por los sucesores de González Carvajal y de Sandino; incluso el propio intendente que la firmó no tardó mucho en contravenirla, constituyendo esta concordia un nuevo argumento para que los conflictos se recrudecieran a partir de 1807.

Finalmente, en tercer y último lugar, hemos comprobado cómo el gobierno central evitó actuar con contundencia para poner fin a unas disputas que se enquistaron durante décadas, por lo que la estrategia de la Intendencia para tratar de influir en quiénes serían los beneficiarios de las dos varas de su jurisdicción acabó siendo muy útil frente a esta sorprendente tibieza. En el mejor de los casos, en Madrid se limitaban a resolver sobre cuestiones puntuales o a poner fin a los asuntos de mayor gravedad paralizando los procesos y devolviendo todo a la situación que tenía inicialmente. Con el argumento recurrente de ser necesaria más información, el tema se eternizó en el eje Consejo de Castilla - secretaría de Estado y del Despacho de Hacienda hasta el punto de que, el 5 de marzo de 1835, se produjo la supresión definitiva del sistema foral que rigió durante casi siete décadas sin que esa resolución llegase a emitirse. Una combinación de azar y de buena disposición por ambas partes fue lo único que permitió alejar, a partir de 1825, esta cuestión de los asuntos más relevantes en las nuevas colonias. Después de una ocupación francesa y dos periodos constitucionales, con supresión del régimen foral incluida, los problemas y prioridades de ambas pasaron a ser otros. 


\section{BIBLIOGRAFíA}

ABbad, Fabrice et Ozanam, Didier, Les intendants espagnols du XVIIIe siècle (Madrid, Casa de Velázquez, 1992).

Alcázar Molina, Cayetano, Las colonias alemanas de Sierra Morena (Notas y documentos para su historia) (Madrid, Universidad de Murcia, 1930).

Álvarez y CAÑas, María Luisa, Los corregidores de letras en la administración territorial andaluza del siglo XVIII, en Revista de Historia Moderna, 13-14 (1995), pp. 123-149.

—Corregidores y alcaldes mayores: La administración territorial andaluza en el siglo XVIII (Alicante, Publicaciones de la Universidad de Alicante, 2012).

Bernaldo DE Quirós, Constancio, Los reyes y la colonización interior de España desde el siglo XVI al XIX (Madrid, Imprenta Helénica, 1929).

Bernardo Ares, José Manuel, Los alcaldes mayores de Córdoba (1750-1833) (Córdoba, Publicaciones del Monte de Piedad y Caja de Ahorros de Córdoba, 1978).

Capel Margarito, Manuel, La Carolina, capital de las Nuevas Poblaciones (Un ensayo de reforma socio-económica de España en el siglo XVIII) (Jaén, Instituto de Estudios Giennenses, 1970).

Filter Rodríguez, José Antonio, Inmigrantes centroeuropeos en la Andalucía del siglo XVIII. Colonos, familia, sociedad y vida cotidiana en las nuevas poblaciones de Cañada Rosal, El Campillo y La Luisiana (Sevilla, Ayuntamientos de Cañada Rosal y La Luisiana, 2018).

García Cano, María Isabel, El gran proyecto ilustrado de Carlos III y Olavide. Las Nuevas Poblaciones de Andalucia (Fuente Palmera, 1768-1835) (Córdoba, Diputación de Córdoba, 2013).

Hamer Flores, Adolfo, La intendencia de las Nuevas Poblaciones de Sierra Morena y Andalucía, 1784-1835. Gobierno y administración de un territorio foral a fines de la Edad Moderna (Córdoba, Universidad de Córdoba, 2009).

—La epidemia de fiebre amarilla de 1800 y su impacto en La Carlota, capital de las Nuevas Poblaciones de Andalucía, en Trocadero. Revista de Historia Moderna y Contemporánea, 30 (2018), pp. 211-230. [https://doi.org/10.25267/Trocadero.2018.i30.12]

Hamer Flores, Adolfo (ed.), Legislación Histórica Neopoblacional. Disposiciones normativas emanadas del poder central en las Nuevas Poblaciones de Sierra Morena y Andalucía (17671835) (Madrid, Bubok Publishing, 2018).

Juan Vidal, Josep y Martínez Ruzz, Enrique, Politica interior y exterior de los Borbones (Madrid, Istmo, 2001).

López de Sebastián, José, Reforma agraria en España. Sierra Morena en el siglo XVIII (Madrid, Editorial ZYX, 1968).

Martínez Aguilar, Joaquin, Ignacio Pablo Sandino de Castro (1766-1833). Abogado, alcalde mayor de La Carlota, diputado en Cortes. Ampliaciones a su bibliografía, en VÁzQuez Lesmes, Rafael y Villas Tinoco, Siro (coords.), Actas del VI Congreso Histórico sobre Nuevas Poblaciones (Córdoba, Junta de Andalucía, 1994), pp. 325-334.

Mercurio Histórico y Político que contiene el estado presente de la Europa, lo sucedido en todas las cortes, los intereses de los principes y generalmente todo lo más curioso, perteneciente al mes de julio de 1779 (Madrid, Imprenta Real de la Gazeta, 1779).

Novísima recopilación de las Leyes de España. Dividida en XII Libros en que se reforma la Recopilación publicada por el señor don Felipe II en el año de 1567, reimpresa últimamente en el de 1775, y se incorporan las pragmáticas, cédulas, decretos, órdenes y resoluciones reales, y otras providencias no recopiladas y expedidas hasta el de 1804 (Madrid, 1805), III.

Pérez Estévez, Rosa María, La España de la Ilustración (Madrid, Actas Editorial, 2002). 
Pérez-Sauquillo y Cádiz, Carlos, Historia de La Carolina, antigua capital de las Nuevas y Reales Poblaciones de Sierra Morena, en ÉL Mismo, Antología breve (Trabajos inéditos) (Sevilla, Librería San José, 1970), pp. 37-137.

Pérez-Schmid Fernández, Francisco José, Colonos y propietarios de las Nuevas Poblaciones de Sierra Morena (Sevilla, Fundación de Municipios Pablo de Olavide, 2020).

Real Cédula de Su Magestad y señores de su Consejo que contiene la Instrucción, y fuero de población, que se debe observar en las que se formen de nuevo en la Sierramorena con naturales, y estrangeros Católicos. Año 1767 (Madrid, Oficina de Antonio Sanz, 1767).

Sánchez-Batalla Martínez, Carlos, La Carolina en el entorno de sus colonias gemelas y antiguas poblaciones de Sierra Morena. Prehistoria a 1835 (Jaén, Caja Rural de Jaén, 1998-2003), 4 vols.

- Almuradiel y Venta de Cárdenas. Apuntes bistóricos (Ciudad Real, Ayuntamiento de Almuradiel y Asociación de Venta de Cárdenas, 2005).

Señán y VelázQuez, Joseph, Guía o estado general de la Real Hacienda de España. Parte primera. Año de 1804 (Madrid, Imprenta de Vega y Compañía, 1804).

- Guía o estado general de la Real Hacienda de España. Año de 1806 (Madrid, Imprenta de Vega y Compañía, 1806).

Tubío Adame, Francisco, Historia de la colonia de Fuente Palmera (1768-1900) (Córdoba, Diputación de Córdoba, 2010).

Vázquez Lesmes, Rafael, Las Nuevas Poblaciones en las Cortes de Cádiz, en Avilés FernÁndez, Miguel y Sena Medina, Guillermo (eds.), Carlos III y las Nuevas Poblaciones (Córdoba, Universidad de Córdoba, 1988), II, pp. 103-120.

-Un pueblo de alemanes en la campiña cordobesa. San Sebastián de los Ballesteros (Córdoba, Diputación de Córdoba, 2015). 